\title{
Human Rights Council
}

Twenty-fifth session

Agenda item 3

Promotion and protection of all human rights, civil, political, economic, social and cultural rights,

including the right to development

Report of the Special Rapporteur on the right to food, Olivier De Schutter

Final report: The transformative potential of the right to food*

\section{Summary}

In the present report, submitted to the Human Rights Council in accordance with its resolution 22/9, the Special Rapporteur on the right to food draws the conclusions from his mandate, showing the connections between his various contributions.

\footnotetext{
* The annex to the present report is reproduced as received, in the language of submission only.
} 


\section{Contents}

I. Introduction

Paragraphs

II. The diagnosis

13

III. What food systems are expected to deliver

2-12 3

A. Sustainable production.

13-31 7

B. Sustainable consumption

16-17 8

C. Poverty reduction

18-23 9

D. A new paradigm

24-28 11

29-31 13

IV. The interdependence of reforms .

32-34 13

V. The way forward

35-49 14

A. Rebuilding local food systems

36-39 15

B. Deploying national strategies

40-44 16

C. Shaping an enabling international environment

45-49 $\quad 18$

VI. Conclusion

$50 \quad 20$

Annex

Overview of key recommendations 


\section{Introduction}

1. Over the past six years, the Special Rapporteur on the right to food has conducted country visits in thirteen countries: Benin, Cameroon, Madagascar and Malawi, low-income countries; Brazil, China, Guatemala, Malaysia, Mexico, Nicaragua, South Africa and the Syrian Arab Republic, middle-income countries; and Canada, a high-income country. He also undertook missions to the World Trade Organization (WTO) and to the Food and Agriculture Organization of the United Nations (FAO), in order to assess their contributions to the realization of the right to food. Following his initial report presenting his programme of work, he prepared 10 interim reports on a range of thematic issues, in addition to two special reports on the global food price crisis requested by the Human Rights Council in resolution S-7/1, at its special session on the global food crisis. He also prepared seven briefing notes, exploring areas that he could not address in sufficient detail in his official reports. In this final report, he presents his main conclusions. An overview of key recommendations made in his past thematic reports to the Human Rights Council and the General Assembly is appended as an annex.

\section{The diagnosis}

2. The right to food is the right of every individual, alone or in community with others, to have physical and economic access at all times to sufficient, adequate and culturally acceptable food that is produced and consumed sustainably, preserving access to food for future generations. ${ }^{1}$ Individuals can secure access to food (a) by earning incomes from employment or self-employment; (b) through social transfers; or (c) by producing their own food, for those who have access to land and other productive resources. Through these channels, which often operate concurrently, each person should have access to a diet that "as a whole contains a mix of nutrients for physical and mental growth, development and maintenance, and physical activity that are in compliance with human physiological needs at all stages throughout the life cycle and according to gender and occupation". ${ }^{2}$ Thus, the normative content of the right to food can be summarized by reference to the requirements of availability, accessibility, adequacy and sustainability, all of which must be built into legal entitlements and secured through accountability mechanisms. The Special Rapporteur's country missions have been situated within this analytical framework.

3. Because of the various channels though which access to food can be achieved, the creation of decent jobs in the industry and services sectors plays an essential role in securing the right to food, as does the provision of social protection. The right to food overlaps in this regard with the right to work and the right to social security, guaranteed under articles 6 and 9 of the International Covenant on Economic, Social and Cultural Rights. While addressing these issues in his thematic reports, the Special Rapporteur has focused most of his work on how food systems might be reformed to ensure a fuller realization of the right to adequate food. Indeed, the beginning of his mandate coincided with the global food price crisis of 2008, and the Special Rapporteur made it a priority to ensure that global and national efforts to address the crisis would be grounded in the right to food. While most of the initiatives that were adopted to strengthen the ability of countries to increase their own production and meet a greater share of their own food needs focused on supporting small-scale farmers, they did not include mechanisms for monitoring

\footnotetext{
${ }^{1}$ Committee on Economic, Social and Cultural Rights, general comment No. 12 on the right to adequate food, paras. 6 and 7 .

2 Ibid., para. 9.
} 
progress and accountability, or for ensuring that food producers and consumers participated in policymaking processes. They did not focus on the most vulnerable and they often failed to guarantee the transformation of support schemes into legal entitlements.

4. Most stakeholders agree, in general terms, on the urgent need for reform. Measured against the requirement that they should contribute to the realization of the right to food, the food systems we have inherited from the twentieth century have failed. Of course, significant progress has been achieved in boosting agricultural production over the past fifty years. But this has hardly reduced the number of hungry people, and the nutritional outcomes remain poor. Using a new method for calculating undernourishment that began with the 2012 edition of the State of Food Insecurity in the World report, United Nations agencies estimate hunger in its most extreme form to have decreased globally from over 1 billion in 1990-1992, representing 18.9 per cent of the world's population, to 842 million in 2011-2013, or 12 per cent of the population. ${ }^{3}$ However, these figures do not capture short-term undernourishment, because of their focus on year-long averages; they neglect inequalities in intra-household distribution of food; and the calculations are based on a low threshold of daily energy requirements that assume a sedentary lifestyle, whereas many of the poor perform physically demanding activities. ${ }^{4}$

5. Calorie intake alone, moreover, says little about nutritional status. Lack of care or inadequate feeding practices for infants, as well as poor health care or water and sanitation, also play a major role. As detailed by the Special Rapporteur (see A/HRC/19/59), even when food intake is sufficient, inadequate diets can result in micronutrient deficiencies such as a lack of iodine, of vitamin A or of iron, to mention only the deficiencies that are the most common in large parts of the developing world. Globally, over 165 million children are stunted - so malnourished that they do not reach their full physical and cognitive potential - and 2 billion people globally lack vitamins and minerals essential for good health. Too little has been done to ensure adequate nutrition, despite the proven long-term impacts of adequate nutrition during pregnancy and before a child's second birthday, both in low-income countries where undernutrition is the major concern ${ }^{5}$ and in middle- and high-income countries. ${ }^{6}$ Moreover, inadequate diets are a major contributing factor to the increase of non-communicable diseases occurring now in all regions of the world. Worldwide, the prevalence of obesity doubled between 1980 and 2008. By 2008, 1.4 billion adults were overweight, including 400 million who were obese and therefore at heightened risk of type 2 diabetes, heart disease or gastrointestinal cancers. ${ }^{7}$

6. The exclusive focus on increasing agricultural production has also had severe environmental impacts. The twentieth-century "Green Revolution" technological package combined the use of high-yielding plant varieties with increased irrigation, the mechanization of agricultural production and the use of nitrogen-based fertilizers and

${ }^{3}$ FAO, International Fund for Agricultural Development and World Food Programme, The State of Food Insecurity in the World 2013: The Multiple Dimensions of Food Security (Rome, 2013), p. 8.

4 F.M. Lappé and others, "How we count hunger matters", Ethics and International Affairs, issue 27.3 (2013).

5 It has been calculated that for any $\$ 1$ spent on reducing stunting, $\$ 44.50$ in returns, as a result of improved earnings, could be expected: J. Hoddinott, M. Rosegrant and M. Torero, "Hunger and malnutrition", Copenhagen Consensus 2012 challenge paper.

6 A study carried out in the United States shows that access to food stamps in childhood leads to a significant reduction in the incidence of obesity, high blood pressure and diabetes in later life and, for women, an increase in economic self-sufficiency: H.W. Hoynes, D.W. Schanzenbach and D. Almond, "Long-run impacts of childhood access to the safety net", National Bureau of Economic Research Working Paper 18535 (November 2012).

7 World Health Organization, World Health Statistics 2012, p. 36. 
pesticides. Thanks to State support in the form of subsidies and marketing, this was effective in increasing the production volumes of major cereals (particularly maize, wheat and rice) and of soybean. The Green Revolution was an attempt to meet the challenge as it was framed at the time: to ensure that increases in agricultural productivity would match population growth and the dietary transition facilitated by rising incomes. It led, however, to an extension of monocultures and thus to a significant loss of agrobiodiversity and to accelerated soil erosion. The overuse of chemical fertilizers polluted fresh water, increasing its phosphorus content and leading to a flow of phosphorus to the oceans that is estimated to have risen to approximately 10 million tons annually. Phosphate and nitrogen water pollution is the main cause of eutrophication, the human-induced augmentation of natural fertilization processes which spurs algae growth that absorbs the dissolved oxygen required to sustain fish stocks. ${ }^{8}$

7. The most potentially devastating impacts of industrial modes of agricultural production stem from their contribution to increased greenhouse gas emissions. Together, field-level practices represent approximately 15 per cent of total human-made greenhouse gas emissions, in the form of nitrous oxide $\left(\mathrm{N}_{2} \mathrm{O}\right)$ from the use of organic and inorganic nitrogen fertilizers, methane $\left(\mathrm{CH}_{4}\right)$ from flooded rice fields and livestock, and carbon dioxide $\left(\mathrm{CO}_{2}\right)$ from the loss of soil organic carbon in croplands and, due to intensified grazing, on pastures. In addition, the production of fertilizers, herbicides and pesticides, the tillage, irrigation and fertilization, and the transport, packaging and conservation of food require considerable amounts of energy, resulting in an additional 15 to 17 per cent of total man-made greenhouse gas emissions attributable to food systems. ${ }^{9}$ The resulting climate changes could seriously constrain the potential productivity of current agricultural methods. For some countries, the changing climate conditions of the past thirty years already appear to have offset a significant portion of the increases in average yields that arose from technology, carbon dioxide fertilization and other factors. ${ }^{10}$ Under a business-as-usual scenario, we can anticipate an average of 2 per cent productivity decline over each of the coming decades, with yield changes in developing countries ranging from -27 per cent to +9 per cent for the key staple crops. ${ }^{11}$

8. The Special Rapporteur has shown that, partly as a result of climate change, but also due to unsustainable and destructive fishing practices and distorting subsidies, the productivity of global fisheries as a source of food is declining (see A/67/268). The unsustainable production of meat is another area of concern. An FAO study, prepared in advance of the High-level Expert Forum on How to Feed the World in 2050, estimated that annual meat production would have to reach 470 million tons to meet projected demand in 2050, an increase of about 200 million tons in comparison to the levels of 2005-2007. ${ }^{12}$ This is entirely unsustainable. Over one third of the world's cereals are already being used

${ }^{8}$ H.W. Paerl and V.J. Paul, "Climate change: links to global expansion of harmful cyanobacteria", Water Research, vol. 46, No. 5 (2012), pp. 1349-1363; M.F. Chislock and others, "Eutrophication: Causes, consequences, and controls in aquatic ecosystems", Nature Education Knowledge, vol. 4, No. 4 (2013), p. 10.

9 High-level Panel of Experts on Food Security and Nutrition, Food Security and Climate Change, HLPE report No. 3 (June 2012). This is confirmed by more recent estimates: see S. Vermeulen, B. Campbell and J. Ingram, "Climate change and food systems", Annual Review of Environment and Resources, vol. 37 (2012), pp. 195-222.

10 D.B. Lobell, W. Schlenker and J. Costa-Roberts, "Climate trends and global crop production since 1980", Science, vol. 333, No. 6042 (2011), pp. 616-620.

11 G.C. Nelson and others, Climate Change: Impact on Agriculture and Costs of Adaptation (International Food Policy Research Institute, 2009).

12 FAO, "How to feed the world in 2050", at www.fao.org/fileadmin/templates/wsfs/docs/expert_paper/How_to_Feed_the_World_in_2050.pdf 
as animal feed, and if current trends continue, this will rise to 50 per cent by 2050. Demand for meat diverts food away from poor people who are unable to afford anything but cereals. Concentrated animal feeding operations, in which industrial quantities of meat are produced, have widely reported negative environmental impacts. Continuing to feed cereals to growing numbers of livestock will aggravate poverty and environmental degradation.

9. Globally, livestock production employs 1.3 billion people and sustains livelihoods for about 900 million of the world's poor. As a major source of protein intake, meat and dairy production is a potential component in tackling undernourishment, and there are sustainable modes of meat production. But in high-income countries, the net health impacts of meat consumption are turning negative: at current levels, it is contributing to chronic diseases, including obesity, type 2 diabetes, cardiovascular diseases and cancer. ${ }^{13}$ Moreover, the industrial model of cereal-fed livestock production as well as the apparently limitless expansion of pastures is creating problems that must be addressed urgently. ${ }^{14}$ In 2006, FAO estimated that grazing occupied an area equivalent to 26 per cent of the icefree terrestrial surface of the planet, while 33 per cent of total arable land was dedicated to feedcrop production - maize and soybean in particular. Thus, livestock production accounted for 70 per cent of all agricultural land and 30 per cent of the land surface of the planet, ${ }^{15}$ and the expansion of pastures and feed crops is a major source of deforestation, especially in Latin America. The FAO study estimated that the livestock sector was responsible for 18 per cent of greenhouse gas emissions measured in $\mathrm{CO}_{2}$ equivalent - a larger share than transport. Once livestock respiration and the loss of greenhouse gas reductions from photosynthesis that are foregone by using large areas of land for grazing or feedcrops are taken into account, livestock is found to be responsible for 51 per cent of anthropogenic greenhouse gas emissions, so that a 25 per cent reduction in livestock products worldwide between 2009 and 2017 could result in a 12.5 per cent reduction in global atmospheric greenhouse gas emissions. ${ }^{16}$ The precise figures remain debated, but there is no doubt in the scientific community that the impacts of livestock production are massive.

10. Finally, because global food systems have been shaped to maximize efficiency gains and produce large volumes of commodities, they have failed to take distributional concerns into account. The increases in production far outstripped population growth during the period from 1960 to 2000. But these increases went hand in hand with regional specialization in a relatively narrow range of products, a process encouraged by the growth of international trade in agricultural products. The associated technological and policy choices concentrated benefits in the hands of large production units and landholders at the expense of smaller-scale producers and landless workers, resulting in the growth of inequality in rural areas and a failure to address the root causes of poverty. Of course, there were important evolutions throughout the period. The 1960s and 1970s were characterized by a State-led type of agricultural development, under which governments, eager to provide urban populations with affordable food or to export raw commodities in order to finance import substitution policies, either paid farmers very low prices for the crops produced or supported only the largest producers who could be competitive on global markets, thus accelerating rural migration. In the 1980s, the introduction in most low-income countries of

13 Arnold Tukker and others, "Environmental impacts of changes to healthier diets in Europe", Ecological Economics, vol. 70, No. 10 (2011), p. 1776.

14 The background research by the Columbia Environmental Law Clinic supporting this section of the report is gratefully acknowledged.

15 FAO, Livestock's Long Shadow: Environmental Issues and Options (Rome, 2006).

16 R. Goodland and J. Anhang, "Livestock and climate change: what if the key actors in climate change are cows, pigs, and chickens?", World Watch, November/December 2009. 
structural adjustment policies resulted in a retreat of the State from agricultural development. It was anticipated that trade liberalization and the removal of price controls would encourage private investment, making up for the reduction of State support. Overproduction in the highly subsidized farming sectors of rich countries put downward pressure on agricultural prices, however, discouraging the entry of private investors into agriculture in developing countries. If there was private investment at all, it went to a narrow range of cash crops grown for export markets.

11. The consequences are well known. Because small-scale farming was not viable under these conditions, many rural households were relegated to subsistence farming, surviving only by diversifying their incomes. Others migrated to the cities, a rural exodus that in Africa accounted for at least half of all urban growth during the 1960s and 1970s and about 25 per cent of urban growth in the 1980s and 1990s. At the same time, the dependence of low-income countries on food imports grew significantly. Many of the least developed countries are still primarily agricultural, yet, in part because they have to repay their foreign loans in hard currency, they export a narrow range of commodities and therefore find themselves highly vulnerable to price shocks on international markets for these products. Their food bills have soared - the combined result of population growth and a lack of investment in local agricultural production and food processing to meet local needs. When the prices of agricultural products suddenly increased in 2008 in the wake of higher oil prices and speculation, the least developed countries found themselves trapped. The imbalances in the food system, which had been building up over the previous forty years, suddenly became visible, and the human consequences too important to ignore (see $\mathrm{A} / \mathrm{HRC} / 9 / 23$ and $\mathrm{A} / \mathrm{HRC} / 12 / 31)$.

12. Indeed, many least developed countries have succumbed to a vicious cycle. As they were confronted from the 1960 s to the 1990 s with strong population growth and rural-tourban migration, their governments had no choice but to depend more on food aid or to import more food products. This made it even more difficult for their own farmers to make a decent living from farming, as they faced increased dumping of heavily subsidized foodstuffs on domestic markets. In effect, the import of low-priced food products functioned as a substitute for improved wages for workers in the non-agricultural sectors, and for the establishment of social protection floors for all. As the Special Rapporteur noted in the report he prepared following his mission to WTO (A/HRC/10/5/Add.2), this was perhaps a convenient solution so long as the prices of basic food commodities remained stable or were declining. However, with higher and increasingly volatile prices, it results in new threats to the right to food of net food buyers and is a recipe for social and political instability. Furthermore, the increased reliance on food imports is a major cause of "nutrition transition" in the developing world, by which nutritionists mean the shift to processed foods richer in salt, sugar and saturated fats - foods that have a long shelf life and are attractive to urban populations and younger generations, but are often less nutritious and less healthy. ${ }^{17}$

\section{What food systems are expected to deliver}

13. There is broad agreement on the diagnosis summarized above. Indeed, it is this diagnosis that explains the major efforts to reinvest in the agricultural sector in low-income countries since 2008 , to do so in a more sustainable way, and to take nutrition into account in agricultural policies. These efforts include significant increases in public budgets

17 A/HRC/10/5/Add.2 (mission to WTO), para. 32; A/HRC/19/59/Add.1 (mission to China), paras. 20 and 21; A/HRC/19/59/Add.2 (mission to Mexico), para. 50; A/HRC/19/59, paras. 32-35. 
dedicated to agriculture, encouraged for instance by the Comprehensive Africa Agriculture Development Programme under the New Partnership for Africa's Development (NEPAD); increases in the share of development cooperation budgets going to agriculture, through bilateral and multilateral channels; initiatives such as Scaling Up Nutrition; and the renewed interest of the private sector in agricultural investment. However, while governmental and non-governmental actors agree on the need for reform, disagreements persist on the way forward.

14. Many view productivity improvements in agriculture as key to addressing hunger and malnutrition. This approach is still as influential today as it was in the 1960s, in part because of increasing demand for agricultural production (for both food and non-food uses) and the anticipated further increases as a result of population growth, higher incomes, and shifting diets linked to urbanization. Thus, FAO estimated in 2009 that a 70 per cent increase in global agricultural production was required by 2050 in comparison to the levels of 2005-2007, taking into account an annual average growth in gross domestic product (GDP) of 2.4 per cent between 2030 and 2050 and assuming that about 290 million people would still be undernourished by 2050 . This estimate was widely cited to justify investments in technology-based solutions to respond to a challenge presented as a primarily quantitative one.

15. Given the threats that food systems face, particularly those linked to climate change and soil degradation, and given the potential of productivity improvements to raise the incomes of small-scale food producers, investments in raising productivity are needed. However, a narrow focus on improved productivity risks ignoring the wide range of other variables that foresight exercises should take into account. ${ }^{18}$ Moreover, the deeper debate concerns not whether productivity should be raised, but how to achieve this. Increasing yields alone will not do. Any prescription to increase yields that ignores the need to transition to sustainable production and consumption, and to reduce rural poverty, will not only be incomplete; it may also have damaging impacts, worsening the ecological crisis and widening the gap between different categories of food producers.

\section{A. Sustainable production}

16. Food systems are not only at great risk from climate change; as noted above, they also are a major contributor to the emissions of greenhouse gases that are responsible for such changes. This is one major reason why a shift to agroecological modes of production is urgently called for (see $\mathrm{A} / \mathrm{HRC} / 16 / 49)$. As a way to improve the resilience and sustainability of food systems, agroecology is now supported by an increasingly broad part of the scientific community. ${ }^{19}$ It features prominently in the International Assessment of Agricultural Knowledge, Science and Technology for Development ${ }^{20}$ and in

18 See, for example, Agrimonde: Scenarios and Challenges for Feeding the World in 2050, (INRA (French National Institute for Agricultural Research) and CIRAD (French Agricultural Research Centre for International Development), 2009); and T. Wise and K. Sundell, Rising to the Challenge: Changing Course to Feed the World in 2050 (ActionAid USA, 2013).

19 A. Wezel and V. Soldat, "A quantitative and qualitative historical analysis of the scientific discipline of agroecology”, International Journal of Agricultural Sustainability, vol. 7, No. 1 (2009), pp. 3-18.

20 International Assessment of Agricultural Knowledge, Science and Technology for Development, "Summary for decision-makers of the global report" (April 2008), finding 7. 
recommendations from the United Nations Environment Programme ${ }^{21}$ as well as other international agencies. ${ }^{22}$

17. Agroecology refers to a range of agronomic techniques, including intercropping, the recycling of manure and food scraps into fertilizers, and agroforestry, that reduce the use of external inputs and maximize resource efficiency. It is consistent with, and complementary to, genetic improvement, as done by the CGIAR (formerly known as the Consultative Group on International Agricultural Research) research centres through marker-assisted breeding, and as done by generations of farmers cultivating landraces. There are strong environmental arguments in favour of agroecology. But agroecology also provides other social and health benefits. Diverse farming systems contribute to more diverse diets for the communities that produce their own food, thus improving nutrition. ${ }^{23}$ Because agroecology reduces the cost of farming by minimizing the use of expensive inputs, it improves the livelihoods of farming households, particularly the poorest households. And it supports rural development: because it is knowledge-intensive and generally more labour-intensive, it creates employment opportunities in rural areas. Though easier to implement on smallersized farms, agroecological techniques can be disseminated on a large scale, and should also inspire reforms in how large production units operate.

\section{B. Sustainable consumption}

18. Far greater attention should also be paid to demand-side issues. Three priorities emerge in particular. A first priority is to mitigate the negative impacts of industrial livestock production by discouraging the increase in demand for meat where meat consumption has already reached levels that are more than sufficient to satisfy dietary needs. A range of options might be considered. They include rethinking taxes and subsidies to discourage the most polluting modes of production and to encourage the shift from ruminants to poultry for a more efficient conversion of cereals into meat protein; reducing methane emissions from enteric fermentation by increasing the level of starch or rapidly fermentable carbohydrates in animal feed, which reduces excess hydrogen and subsequent methane formation; or improving manure management and land management. But almost every study recognizes that solving the environmental problems caused by livestock farming will require reducing the demand for animal products. ${ }^{24}$

19. A second priority is to constrain the demand for liquid biofuels in the transport sector of high-income countries. Mandates for the consumption of biofuels in transport fuels in the United States of America and the European Union, and support to the production of biofuels in the form of subsidies, have significantly increased demand for agricultural commodities over the past 10 years. ${ }^{25}$ This has represented a major source of price volatility on agricultural markets and one of the most important factors explaining the global food price crisis of $2008,{ }^{26}$ in part because these policies have strengthened the links

21 United Nations Environment Programme, The Environmental Food Crisis (Nairobi, 2009).

${ }^{22}$ FAO and Bioversity International, Sustainable agriculture and rural development policy brief 11 , 2007.

23 F.A.J. DeClerck and others, "Ecological approaches to human nutrition", Food and Nutrition Bulletin, vol. 32, supplement 1 (2011), pp. 41S-50S.

24 R.C. Ilea, "Intensive livestock farming: Global trends, increased environmental concerns, and ethical solutions", Journal of Agricultural and Environmental Ethics, vol. 22 (2009), p. 153.

25 D. Zilberman and others, "The impact of biofuels on commodity food prices: assessment of findings", American Journal of Agricultural Economics (2012), pp. 1-7. doi: 10.1093/ajae/aas037.

26 R. Naylor and W. Falcon, "Food security in an era of economic volatility", Population and Development Review, vol. 36 (2010), pp. 693-723. 
between the food and energy markets: the conversion of crops for ethanol or biodiesel represents an economic opportunity especially where oil prices are high, which in itself already impacts on food prices. The push for biofuels has also exacerbated pressures on natural resources, as the production of energy crops competes for land and water with other uses, including the production of food, feed and fibre, environmental conservation and carbon sequestration, and urbanization or industrial projects (A/65/281). Foresight studies have suggested that, if current mandates are implemented, the price of cereals and other crops could be 35 per cent higher by 2030 than under a reference scenario where biofuel consumption remained constant at 2008 levels, putting an estimated 136 million more people at risk of hunger. ${ }^{27}$

20. Agroenergy may improve access to clean energy in many developing countries and reduce their dependency on fossil-fuel energies. Under certain conditions, it can improve the incomes of small-scale farmers. But the rapid expansion of the demand for liquid agrofuels for transport in rich countries results in higher food prices and speculation on farmland, and encourages land grabs on a large scale. For this reason, the Special Rapporteur has called for abandoning mandates on the consumption and production of biofuels and for improving international cooperation in this area, to mitigate the impacts of increased levels of agrofuel production on the prices of foodstuffs (A/HRC/12/31, paras. 23-25). This call was reiterated in 2013 by the High-Level Panel of Experts on Food Security and Nutrition, which advises the Committee on World Food Security. ${ }^{28}$

21. A third priority is to take significant measures to improve the efficiency of food systems, by reducing losses and waste. A 2011 study estimates that 1.3 billion tons of food produced for human consumption - about one third of the total - is lost or wasted. ${ }^{29}$ In lowincome countries, losses occur primarily as a result of inadequate storage and packaging and processing facilities, and a poor connection of farmers to markets, resulting in economic losses for food producers. In contrast, the levels of per capita food waste are much higher in rich countries than in developing countries: while a consumer in subSaharan Africa or South and South-East Asia wastes from 6 to $11 \mathrm{~kg}$ per year, this amount is between 95 and $115 \mathrm{~kg}$ per year in Europe and North America.

22. These inefficiencies result in food production exerting a much higher pressure on natural resources than would otherwise occur. ${ }^{30}$ Various measures could be taken in response. They include improving storage and marketing facilities, especially in developing countries; helping farmers to organize themselves in ways that avoid systematic net overproduction, for example by compensating the losses of some with the surplus production of others; improving access to credit for farmers to reduce the need for premature harvesting in order to satisfy food needs or to obtain cash; avoiding reliance on high "appearance quality standards" which lead to fresh produce being rejected if it does not present the required qualities of shape, size or colour; and developing direct farmer-toconsumer marketing.

23. Though apparently unrelated to one another, these issues - industrial livestock production, liquid biofuels for transport, and waste - share certain common characteristics.

27 G. Fischer, "How can climate change and the development of bioenergy alter the long-term outlook for food and agriculture?", Looking Ahead in World Food and Agriculture: Perspectives to 2050 (FAO, 2011), pp. 129 and 133-135.

28 High-level Panel of Experts on Food Security and Nutrition, "Biofuels and food security", HLPE report No. 5 (June 2013).

29 J. Gustavsson and others, Global Food Losses and Food Waste: Extent, Causes and Prevention (FAO, 2011).

30 FAO, Food Wastage Footprint: Impacts on Natural Resources (2013). 
As the Special Rapporteur has also highlighted with regard to the exploitation of fish stocks (A/67/268, paras. 21-23 and 29-32; A/HRC/19/59/Add.4 (Madagascar), paras. 38-43), they present the international community with specific challenges that result from globalized markets connecting populations with widely diverging purchasing powers, in the context of finite resources. The reason why large areas of farmland can be dedicated to producing feedstock to satisfy the overconsumption of meat in affluent societies, or to fuel their cars, is that consumers in rich countries can command the resources that will allow their lifestyles to continue unchallenged. Similarly, the huge amounts of retail and consumer waste in rich countries are correlated with the fact that, as incomes have grown, the proportion of the household budget spent on food has diminished. This highlights the limits of the argument that the expansion of trade in agricultural commodities leads to efficiency gains by encouraging a division of labour according to comparative advantage: in fact, the expansion of trade also has resulted in the luxury tastes of the richest parts of the world being allowed to compete against the satisfaction of the basic needs of the poor. ${ }^{31}$ Ultimately, this creates a highly worrying competition for the natural resources needed for food production, particularly land. While a purely Malthusian view of land as finite oversimplifies the issue of competition for scarce resources, as the productivity of land can be increased to a certain extent and as some land can still be brought into production, recent research has highlighted the considerable social and ecological costs of doing so. Once these trade-offs are taken into account, this research shows, there is significantly less cropland available for future expansion than has been traditionally assumed in most scenarios. $^{32}$

\section{Poverty reduction}

24. Finally, food and agricultural policies should address the distributional issues that result in large groups of the rural population in developing countries being too poor to satisfy their basic needs. Small-scale food producers and the landless rural poor, including many farmworkers who barely survive from their labour on large plantations, represent a majority of those living in extreme poverty. Yet, the promotion in the past of export-led agriculture, often based on the exploitation of a largely disempowered workforce, operated at the expense of family farms producing food crops for local consumption. This resulted in a paradoxical situation in which many low-income countries, though they are typically agriculture-based, raw commodity-exporting economies, are highly dependent on food imports, sometimes supplemented by food aid, because they have neglected to invest in local production and food processing to feed their own communities (A/HRC/9/23, annex I, para. 5). It also led to increased rural poverty and the growth of urban slums, and to the inability of governments to move to a more diversified economy: whereas such a diversification requires adequate infrastructure, a qualified workforce, and a consumer market allowing producers of manufactured goods, or service providers, to achieve economies of scale, none of this can happen when half of the population is condemned to extreme deprivation. Thus, the lack of support for small-scale farmers has not only weakened own-production as a means of access to food. It has also had severe impacts on the two other channels through which the right to food can be realized, as it has reduced

31 E. Lambin and P. Meyfroidt, "Global land use change, economic globalization, and the looming land scarcity", Proceedings of the National Academy of Sciences of the United States of America, vol. 108, No. 9 (March 2011), pp. 3465-3472.

32 E. Lambin and others, "Estimating the world's potentially available cropland using a bottom-up approach", Global Environmental Change, vol. 23, No. 5 (October 2013), pp. 892-901. Available from http://dx.doi.org/10.1016/j.gloenvcha.2013.05.005; E. Lambin, "Global land availability: Malthus versus Ricardo”, Global Food Security, vol. 1, No. 2 (December 2012), pp. 83-87. 
employment opportunities in the industry and services sectors, making it impossible for governments to finance social protection schemes.

25. Improving support to smallholders is therefore essential in achieving local food security. The Special Rapporteur explored different tools to achieve this. At the heart of his proposals lies the question of how to ensure that the freedom of choice of small-scale food producers is truly respected. This requires pursuing two reform programmes in parallel.

26. On the one hand, food systems must be reshaped in order to be more inclusive of small-scale food producers, who have generally been disadvantaged in the past, both as a result of inequitable food chains and because agricultural technologies have not taken into account their specific needs. With this aim in mind, the Special Rapporteur noted the importance of addressing imbalances of power in food chains, in particular by regulating buyer power in situations where dominant positions may be a source of abuse: this has been an entirely forgotten dimension of the reforms that have been promoted since 2008 (A/HRC/9/23, paras. 35-38; and A/HRC/13/33). He also sought to define the conditions under which contract farming - based on long-term agreements between agricultural producers and buyers - could benefit small-scale farmers, suggesting a variety of business models that could usefully be implemented to support the inclusion of small-scale food producers in the food systems (A/66/262) and noting the importance of supporting farmers' organizations. He called for reforming a regime of intellectual property rights on plant varieties that can make commercially bred varieties inaccessible to the poorest farmers in low-income countries (A/64/170).

27. On the other hand, the right of small-scale food producers not to be forced or coopted into the dominant food systems must be recognized. Respect for their access to productive resources is key in this regard. The Special Rapporteur dedicated a report to access to land as a component of the right to food, identifying the threats posed by the increasing commercial pressures on land and suggesting the adoption of anti-eviction laws as well as tenancy laws (A/65/281; see also A/HRC/9/23, paras. 20-22). He put forward minimum principles and measures to address the human rights challenge regarding largescale acquisitions or leases of land (A/HRC/13/33/Add.2). He suggested that the promotion of agroecology, already mentioned above, could be of particular importance to cashstrapped farmers working in the most difficult environments and unable or unwilling to enter into more highly capitalized forms of agriculture. He also emphasized the need to support farmers' seed systems, which are threatened by the almost exclusive focus of public policies on high-yielding plant varieties - which, although they perform well under the right set of conditions, may be more costly and less suitable in specific agroecological environments (A/64/170). He extended his study to artisanal fishers, expressing the hope that the International Guidelines for Securing Sustainable Small-Scale Fisheries, to be negotiated within the FAO Committee on Fisheries in 2013-2014, would improve the protection of artisanal fishers against the various threats he identified (A/67/268).

28. There is a strong overlap between the recommendations made in these various reports and the Declaration of the Rights of Peasants - Women and Men, adopted in 2008 by the international network of peasant organizations, Via Campesina, which the Human Rights Council Advisory Committee attached to its final study on the advancement of the rights of peasants and other people working in rural areas, submitted in 2012 (A/HRC/19/75). This declaration now forms the basis of the discussions launched on 15 July 2013 within the open-ended intergovernmental working group mandated by the Human Rights Council in its resolution 21/19 to negotiate a United Nations declaration on the rights of peasants and other people working in rural areas. The Special Rapporteur strongly supports this process. In his first report to the Human Rights Council, he already noted that peasants formed a particularly vulnerable group, because of the increased competition for the resources on which they depend, because of the pressures of industrial 
agriculture and because of their weaker ability to organize themselves and, thus, to gain a voice in the political process (A/HRC/9/23, para. 17). The declaration under preparation can be an important tool to improve their protection and to give greater visibility to the specific threats that they face.

\section{A new paradigm}

29. In sum, we have entered a new century, and the questions we face now are different from those of fifty years ago. A new paradigm focused on well-being, resilience and sustainability must be designed to replace the productivist paradigm and thus better support the full realization of the right to adequate food. The equation is complex, but it is one that can be solved.

30. Firstly, certain types of agricultural development can combine increased production, a concern for sustainability, the adoption of robust measures to tackle unsustainable consumption patterns, and strong poverty-reducing impacts. Governments could achieve this by providing strong support to small-scale food producers, based on the provision of public goods for training, storage and connection to markets, and on the dissemination of agroecological modes of production. In addition, measures should be taken to develop local markets and local food processing facilities, combined with trade policies that support such efforts and at the same time reduce the competition between the luxury tastes of some and the basic needs of the others.

31. Secondly, just as multiple food systems must be combined to improve resilience through enhanced diversity, different forms of farming can coexist, each fulfilling a different function. The example of Brazil suggests that family farms can be supported even in the vicinity of highly competitive, large-scale agricultural producers and that such coexistence can be viable, provided the government is aware of the different functions that different agricultural models serve to fulfil, and adopts a balanced approach towards them (A/HRC/13/33/Add.6, paras. 43 and 44). In many countries, however, this coexistence has failed, and the balance has shifted almost entirely in favour of the large-scale export-led agricultural sector. The lesson that emerges is that the transition to agrifood policies that support the realization of the right to food requires major political efforts to restructure support around agroecological, labour-intensive, poverty-reducing forms of agriculture.

\section{The interdependence of reforms}

32. There is a connection between the obstacles faced by low-income countries in their attempt to improve their ability to protect the right to food of their populations, and the need for reform in middle- and high-income countries. While a number of reasons explain the lack of investment in food production to satisfy local needs - including in particular the burden of foreign debt (which leads countries to focus on cash crops for exports) and the often weak accountability of governments to the rural poor (A/HRC/9/23, para. 17) - the addiction to cheap food imports is also caused by massive overproduction in better-off exporting countries, which is stimulated by subsidies going to the largest agricultural producers in those countries, and which ensures access to cheap inputs for the food processing industry. And it is facilitated by the growth of international trade and investment and the corresponding increase of the role of large agribusiness corporations in the food systems.

33. This is the interdependence of reforms. While the rebuilding of local food systems in developing countries is vital to expand opportunities to small-scale food producers and, at the same time, to improve access to fresh and nutritious food for all, it depends 
fundamentally on the reform of food systems in rich countries. Such reform faces significant obstacles, however. The various elements of the food systems have co-evolved over the years, shaped by the productivist paradigm that has dominated the design of food and agricultural policies for decades. The farming sector has become highly dependent on agricultural subsidies that have favoured the production of commodities for the livestock or food processing industry - corn, soybean and wheat, in particular - rather than food, and it has come to rely on cheap fuel for its highly mechanized and input-intensive mode of production, replacing farmers' knowledge. Even without taking into account the subsidies for the consumption of fossil fuels by agricultural producers, countries of the Organization for Economic Cooperation and Development subsidized their farming sector to the amount of $\$ 259$ billion in 2012. This has encouraged the expansion of the food processing industry, thanks to the availability of cheap inputs and the deployment of infrastructure - in the form of silos and processing plants - that has been shaped by and for agro-industry. Large agribusiness corporations have come to dominate increasingly globalized markets thanks to their ability to achieve economies of scale and because of various network effects. In the process, smaller-sized food producers have been marginalized because, although they can be highly productive per hectare of land and highly resource-efficient if provided with adequate support, ${ }^{33}$ they are less competitive under prevalent market conditions. The dominant position of the larger agribusiness corporations is such that these actors have acquired, in effect, a veto power in the political system. Finally, the habits of consumers themselves have changed: in high-income countries, the consumption of highly processed, high-energy (though nutrient-poor) foods has increased year on year, becoming an accepted, unquestioned part of modern life.

34. As noted above, these developments have come at a high ecological cost. Due to the links between agriculture, diets and health, they also impose a considerable burden on health-care systems. They have led, finally, to the depopulation of rural areas. Yet, because these different components of the food systems shaped during the past half-century have strengthened one another, they have become lock-ins, seemingly blocking any real transformative possibilities.

\section{The way forward}

35. Nevertheless, the Special Rapporteur believes that change can be achieved. Actions should be launched at three levels to democratize food security policies, thus weakening existing lock-ins and allowing these policies to shape the new model that he calls for. At the local level, the key to transition is to rebuild local food systems, thus decentralizing food systems and making them more flexible, but also creating links between the cities and their rural hinterland, for the benefit both of local producers and of consumers. At the national level, in addition to support for locally-led innovations, multisectoral strategies should be deployed. Such strategies should trigger a process in which progress is made towards supporting a reinvestment in local food production, focused in particular on small-scale food producers in the countries where they represent a large proportion of the poor; towards the diversification of the economy, to create opportunities for income-generating activities; and towards the establishment of standing social protection schemes, to ensure that all individuals have access to nutritious food at all times, even if they have access neither to productive resources nor to employment. At the international level, greater coordination should be achieved between actions launched at the multilateral, regional and national

33 C. Carletto, S. Savastano and A. Zezza, "Fact or artefact: The impact of measurement errors on the farm size-productivity relationship", Policy Research Working Paper 5908, World Bank (December 2011). 
levels, with a view to creating an enabling international environment - rewarding and supporting domestic efforts towards the realization of the right to food rather than obstructing them. At each of these levels, the right to adequate food has a key role to play to guide the efforts of all actors, to ensure participation of those affected by hunger and malnutrition, and to establish appropriate accountability mechanisms.

\section{A. Rebuilding local food systems}

36. The modernization of food supply chains, together with the implementation of agricultural policies focused more on the production of commodities than on food, has led to the marginalization of local food systems over recent years (A/HRC/13/33, paras. 6-9). This trend must be reversed. Small-scale food producers must be provided with greater opportunities to sell on the local markets, which they can more easily supply without having to be dependent on large buyers. Furthermore, the poorest consumers, who now often rely on large retailers or fast food outlets to feed themselves, must have the possibility to purchase food that is fresh and nutritious, and therefore healthier. These include the urban poor, but in developing countries they also include many small-scale farmers, who often are net food buyers and combine other activities with their role as food producers. ${ }^{34}$ Local food systems can be rebuilt through appropriate investments in infrastructure, packaging and processing facilities, and distribution channels, and by allowing smallholders to organize themselves in ways that yield economies of scale and allow them to move towards higher-value activities in the food supply chain. This would support rural development and the reduction of rural poverty, and slow down rural-to-urban migration.

37. The strengthening of local food systems would also improve the resilience of cities. By 2050, when the world population will have reached 9.3 billion, about 6.3 billion of these inhabitants, more than two in three, will be urban, at current rates of rural-to-urban migration. Under a business-as-usual scenario, the rural population is expected to decline globally after 2020: there will be 300 million fewer rural inhabitants in 2050 than there were in $2010 .^{35}$ As the competition increases between putting land to urban or to industrial use in the urban and peri-urban perimeter, and as increased food supplies create unprecedented logistical challenges for food distribution and transport systems, it is vital that cities assess their food dependencies, identify weaknesses and potential pressure points and, where possible, develop a variety of channels through which they can procure their food. ${ }^{36}$ Urban and peri-urban agriculture, as well as the development of short food chains connecting cities to their local foodshed, will therefore play an increasingly important role.

38. A wide range of social innovations have emerged in recent years to support the rebuilding of local food systems, primarily by reconnecting urban consumers with local food producers. In Canada, the Special Rapporteur learned about a number of initiatives that seek to support relocalized food systems (A/HRC/22/50/Add.1, paras. 17 and 26-32). In Montreal, for instance, urban agriculture initiatives include a community gardening programme managed by the City, and collective gardens managed by community organizations, with impacts that go beyond improved food security and nutrition,

34 See World Bank, World Development Report 2008: Agriculture for Development (Washington, D.C., 2007), p. 109 (showing that in countries such as the Plurinational State of Bolivia (based on 2002 data), Bangladesh (2001), Ethiopia (2000), Viet Nam (1998) or Zambia (1998), the proportion of smallholders who are net food buyers is larger than the proportion who are net sellers).

35 World Urbanization Prospects: The 2011 Revision (United Nations publication, ESA/P/WP/224).

36 See "Food, agriculture and cities: Challenges of food and nutrition security, agriculture and ecosystem management in an urbanizing world" (FAO, 2011). 
contributing also to educational and empowerment goals. ${ }^{37}$ In November 2013, the province of Ontario adopted a Local Food Act (Bill 36), establishing a local food fund and aiming to increase awareness of, access to and demand for local food in the province, as well as supporting local food procurement in public sector institutions (schools, municipalities, hospitals and cafeterias). Meanwhile, Toronto's food strategy includes the Toronto Agricultural Program in support of urban agriculture, and support to a Mobile Good Food Market initiative serving low-income communities. In South Africa, the Special Rapporteur noted with interest the City of Durban/eThekwini Municipality's Agroecology Delivery Programme (A/HRC/19/59/Add.3, paras. 48 and 49). In Brazil, he was impressed by the achievements of the Zero Hunger strategy launched in 2003 (A/HRC/13/33/Add.6, para. 33).$^{38}$ Following the example of Belo Horizonte a decade earlier, this strategy includes a range of programmes that are territory-based and seek to support the ability of "family farmers" to feed the cities: among the innovations are the institutional recognition of family farming and the establishment of a ministry specifically dedicated to meeting their needs (the Ministry for Agrarian Development), a low-income restaurant programme, food banks, community kitchens, cisterns, and the improvement of facilities for the storage of food in rural areas, as well as encouragement of the "social solidarity" economy. Zero Hunger was further strengthened in 2008 with the introduction of the Territories of Citizenship programme, focused on least developed rural territories and including a strong social participation component. Mexico is also stepping up its efforts with the National Crusade against Hunger, which includes a strongly participatory dimension, as the Special Rapporteur could witness first-hand during a visit to the country on 14 and 15 November 2013.

39. The right to food is central to the success of these efforts at rebuilding local food systems. First, a key condition for the success of such strategies is that participation is encouraged at a local level, in order to allow all stakeholders (from the producers to the end consumers) to arrive at a joint diagnosis of which improvements could be made to rebuild the local food system and to propose certain social innovations. Local initiatives informed by social participation will be better informed and therefore more effective in reaching their objectives, and they will result in a more transparent and accountable use of resources. The establishment of local food councils formally linked to municipalities can be one way of achieving this. Second, the right to food provides a way to measure whether the initiatives launched are successful, thus facilitating monitoring. The definition of the right to food recalled above provides a set of indicators to define success, in ways that avoid conflating it with the reduction of income poverty or increased agricultural outputs. Third, crucially, the right to food introduces the dimension of accountability: social innovations aimed at the mobilization of local resources to rebuild food systems through a bottom-up approach will have lasting impacts if they result in commitments that beneficiaries can claim - for instance, commitments to provide certain types of support to local food producers or to deliver adequate food to low-income communities.

\section{B. Deploying national strategies}

40. The Special Rapporteur has consistently encouraged the adoption of national strategies in support of the progressive realization of the right to adequate food, in line with the recommendations of the Committee on Economic, Social and Cultural Rights in its

37 E. Duchemin, F. Wegmuller and A.-M. Legault, "Urban agriculture: multi-dimensional tools for social development in poor neighbourhoods", Field Actions Science Report, vol. 1 (2008), pp. 43-50.

38 See J. Graziano da Silva, M. del Grossi and C. Galvão de França, eds., The Fome Zero (Zero Hunger) Program: The Brazilian Experience (2010). 
general comment No. 12 on the right to adequate food (para. 21) and with guideline 3 of the Voluntary Guidelines to Support the Progressive Realization of the Right to Adequate Food in the Context of National Food Security. He was encouraged by the significant progress made in a number of regions, though especially in Latin America and in Africa, towards implementing these recommendations (A/68/288, paras. 42-46).

41. Such strategies are a key component for the governance of the transition towards sustainable food systems that can contribute to the eradication of hunger and malnutrition. Indeed, regardless of how innovative they may be, local initiatives can only succeed, and be "scaled out" by successful experiments being replicated across large regions, if they are supported, or at least not obstructed, by policies adopted at the national level. Moreover, poor nutritional outcomes are explained by a range of factors, and combating hunger and malnutrition requires taking into account the full set of immediate, underlying and basic causes, at the individual, household and societal level respectively: this calls for a multisectoral approach, involving the full range of relevant ministries. Finally, because food systems are in need of reform, it is not sufficient to protect existing entitlements or to preserve the status quo. Instead, transformative strategies must be adopted, with a view to guaranteeing access to adequate food for all by simultaneously supporting small-scale food producers' ability to produce food sustainably, improving employment opportunities in all sectors and strengthening social protection.

42. For such strategies to succeed, the careful sequencing of actions matters, requiring strong cross-sectoral coordination. For instance, support to small-scale food producers should be paired with investments in local food packaging and processing industries and in food retail, in order to maximize the benefits to the local economy of the growth of the agricultural sector. Support to small-scale food producers should also go hand in hand with investments in the manufacturing and services sectors for the delivery of consumer items, since increased incomes in rural areas have the potential to raise demand for locally traded goods and services: this "consumption linkage" is estimated to be four to five times more important than the "production" linkage between food producers and agro-processing activities. ${ }^{39}$ The multiplier effects are particularly significant where agricultural growth is widely spread across large segments of a very poor population.

43. The gradual substitution of policies focused on low prices of foodstuffs by rightsbased social protection, as a means of ensuring access to adequate food for the poorest groups of the population, again illustrates the importance of a careful sequencing of reforms. Today, 75 to 80 per cent of the world population still does not have access to social security to shield them from the effects of unemployment, illness or disability - not to mention crop failure or soaring food costs. ${ }^{40}$ There is now an international consensus in favour of making the full realization of the right to social security a priority. On 12 June 2012, the International Labour Conference adopted Recommendation No. 202 concerning national floors for social protection, with 453 votes in favour and 1 abstention. The G-20 has subsequently acknowledged the importance of this objective. ${ }^{41}$ In the long run, the establishment of robust social protection schemes in line with this recommendation should protect not only poor households but also vulnerable households against the risk of falling into poverty. Thus, governments would shift away from their exclusive focus on maintaining low prices of food items, a focus that has often come at the expense of food

39 L. Christiaensen, L. Demery and J. Kuhl, "The (evolving) role of agriculture in poverty reduction - an empirical perspective", Journal of Development Economics, vol. 96, No. 2 (November 2011), pp. 239-254.

40 International Labour Organization, Social Protection Floor for a Fair and Inclusive Globalization: Report of the Social Protection Floor Advisory Group (Geneva, 2011), p. xxi.

41 G-20 leaders' declaration, G-20 meeting in Los Cabos, Mexico, 18-19 June 2012, para. 22. 
producers, particularly the least competitive among them. Cash transfers to poor families, such as the Oportunidades programme in Mexico (A/HRC/19/59/Add.2, paras. 21-27), the Bolsa Família in Brazil (A/HRC/13/33/Add.6, para. 33) or the Child Support Grant in South Africa (A/HRC/19/59/Add.3, para. 39), have shown their effectiveness in reducing child poverty, and hunger. As long as gaps remain in social protection, however, food price inflation will continue to be a serious threat to the right to food of low-income households. Thus, while low food prices may not be a long-term solution - both because of the fiscal cost of subsidies to farmers and because a policy focused on keeping prices low may ultimately harm the least competitive food producers - they remain, in the short term, vital. Social protection schemes should be strengthened in all countries, and the social protection agenda and the agricultural agenda should be better aligned with each other, to gradually succeed in making the transition.

44. National strategies grounded in the right to food should be conceived as participatory processes, co-designed by all relevant stakeholders, including in particular the groups most affected by hunger and malnutrition - smallholder producers, fisherfolk, pastoralists, indigenous people, the urban poor, migrants and agricultural workers. Interministerial bodies should be provided with recommendations that can support local initiatives that support the transition to sustainable food systems (A/68/288, paras. 42-46). The strategies should set out objectives that are specific, measurable, attainable, relevant and time-bound. Their rights-based dimensions require that they identify which actor is responsible for which action, and that implementation be supported by independent monitoring in the hands of national human rights institutions or, perhaps preferably, food security and nutrition councils. Because gender-based discrimination violates the right to food of women and girls, the empowerment of women and gender equality, as well as the adoption of social protection schemes that are transformative of gender roles, should be a priority of such strategies. Enhancing the role of women in decision-making at all levels, including within the household, moreover, improves nutritional and health outcomes. And women must be better supported as economic agents in the food systems (A/HRC/22/50). ${ }^{42}$

\section{Shaping an enabling international environment}

45. The progressive realization of the right to food also requires improving global governance. Since its reform in 2009, the Committee on World Food Security (CFS) has been making a major contribution to the global food security agenda. The Special Rapporteur actively participated in this process as a member of the "Friends of the Chair" during the reform phase, and later as a member of the CFS Advisory Group. Perhaps the most immediate success of CFS is the fact that it brings together such a wide variety of stakeholders - governments, of course, but also civil society, international agencies and the private sector - who each provide a different framing of the challenges that the food systems face, thus stimulating a process of collective learning across different constituencies.

46. CFS allows for an iterative process to take place, to gradually arrive at recommendations based on a consensus across various groups of stakeholders. These recommendations are collected in the Global Strategic Framework for Food Security and Nutrition, a first version of which was endorsed in October 2012. ${ }^{43}$ The Framework is a rolling document, conceived to improve coordination and guide synchronized action by a

42 See also Asian Development Bank and FAO, Gender Equality and Food Security: Women's Empowerment as a Tool against Hunger (authored by Olivier De Schutter), 2013.

43 A second version was adopted in October 2013, at the fortieth plenary session of CFS. 
wide range of stakeholders in support of global, regional and country-led actions for the realization of the right to food. It is also a learning tool, as it will be revised in the light of both successes and failures in the implementation of the recommendations, so that policies are gradually improved and the range of options available to States is enlarged.

47. The role of CFS should gain in importance in the future, as we become more aware of the interdependence of efforts at the local, national, regional and global levels, and of the need to accelerate learning. Indeed, just as local-level initiatives cannot succeed without support from national-level right-to-food strategies, efforts at the domestic level require international support to bear fruit. Together with the Special Rapporteur on extreme poverty and human rights, the Special Rapporteur has argued, for instance, for the establishment of a Global Fund for Social Protection, for overcoming financial obstacles and building international solidarity in order to fulfil the right to food and the right to social protection in developing countries, particularly those where vulnerability to covariant risks such as drought and food price volatility are high. ${ }^{44}$ The initiative was presented at the thirty-ninth plenary session of CFS in October 2012, and to the Social Protection Inter-Agency Cooperation Board, as well as in various other forums. The proposal was supported by the European Parliament ${ }^{45}$ and was among the key recommendations that emerged from global consultations led by the High-level Panel of Eminent Persons on the Post-2015 Development Agenda. ${ }^{46}$

48. The ninth Ministerial Conference of WTO, held in Bali, Indonesia, from 3 to 7 December 2013, which failed to place food security above trade concerns, provides a textbook illustration of the need to improve coherence of global governance for the realization of the right to food: no area, not even trade, should be left aside from discussions concerning this paramount objective. ${ }^{47}$ The redefinition of the global development goals provides another opportunity to move towards this objective. In the outcome document of the Rio+20 Conference, entitled "The future we want", Heads of State and Government reaffirmed their "commitments regarding the right of everyone to have access to safe, sufficient and nutritious food, consistent with the right to adequate food and the fundamental right of everyone to be free from hunger." ${ }^{48}$ In its final report of May 2013, the High-level Panel of Eminent Persons on the Post-2015 Development Agenda proposed to include ensuring "food security and good nutrition" among the universal goals and targets to be agreed, with target 5 (a) referring to ending hunger and protecting the right of everyone to have access to sufficient, safe, affordable and nutritious food. Similar conclusions emerged from the Madrid High-level Consultation on Hunger, Food Security and Nutrition in the Post-2015 Development Framework, convened on 4 April 2013. At its fortieth plenary session, building on this emerging consensus, CFS highlighted "the essential role of food security and nutrition and poverty eradication in the elaboration of the

44 See O. De Schutter and M. Sepúlveda, "Underwriting the poor: a global fund for social protection", Briefing Note 7 (October 2012). Available from www.srfood.org.

45 European Parliament resolution of 18 April 2013 on the impact of the financial and economic crisis on human rights, P7_TA(2013)0179, para. 26.

46 Report of the High-level Panel of Eminent Persons on the Post-2015 Development Agenda, A New Global Partnership: Eradicate Poverty and Transform Economies through Sustainable Development (United Nations, May 2013), p. 60.

47 In November 2011, the Special Rapporteur had warned about the risks of a misalignment between the trade and the food security agendas. See O. De Schutter, "The World Trade Organization and the post-global food crisis agenda: putting food security first in the international trade system", Briefing Note 4 (November 2011). Available from www.srfood.org.

48 United Nations Conference on Sustainable Development, "The future we want" (outcome document), para. 108. 
post-2015 development agenda", and it mandated its Bureau to ensure this key objective would be reflected in this agenda. ${ }^{49}$

49. Indeed, it is now time to move from generous intentions to action. The eradication of hunger and extreme poverty is now placed at the top of the political agenda, and through the new sustainable development goals, monitoring will be strengthened at a global level. Grounding these efforts explicitly in the right to food will encourage all the actors involved in the implementation of these goals to acknowledge their duties towards those who are marginalized economically and politically disempowered, and to address the political economy of food systems - in other terms, the question of who decides, on the basis of what information, and under which accountability mechanisms.

\section{Conclusion}

50. The eradication of hunger and malnutrition is an achievable goal. Reaching it requires, however, that we move away from business as usual and improve coordination across sectors, across time and across levels of governance. Empowering communities at the local level, in order for them to identify the obstacles that they face and the solutions that suit them best, is a first step. This must be complemented by supportive policies at the national level that ensure the right sequencing between the various policy reforms that are needed, across all relevant sectors, including agriculture, rural development, health, education and social protection. In turn, local-level and national-level policies should benefit from an enabling international environment, in which policies that affect the ability of countries to guarantee the right to food - in the areas of trade, food aid, foreign debt alleviation and development cooperation - are realigned with the imperative of achieving food security and ensuring adequate nutrition. Understood as a requirement for democracy in the food systems, which would imply the possibility for communities to choose which food systems to depend on and how to reshape those systems, food sovereignty is a condition for the full realization of the right to food. But it is the paradox of an increasingly interdependent world that this requires deepening the cooperation between States.

49 Committee on World Food Security, report on the fortieth session, Rome, 7-11 October 2013 (CFS 2013/40 REPORT), para. 81. 


\section{Annex}

[English only]

\section{Overview of key recommendations}

The following provides a summary of key recommendations made by the Special Rapporteur in past thematic reports, from 2008 to 2013, to the Human Rights Council (at its $9^{\text {th }}, 10^{\text {th }}, 13^{\text {th }}, 16^{\text {th }}, 19^{\text {th }}$, and $22^{\text {nd }}$ sessions) and the General Assembly (at its $63^{\text {rd }}$ to $68^{\text {th }}$ sessions).

\section{A. Ensuring access to resources}

\section{Access to land}

In a context in which commercial pressures on land are increasing, it is crucial that States strengthen the protection of land users (A/65/281) and implement the Voluntary Guidelines on Responsible Governance of Tenure of Land and other Natural Resources. In particular, States should:

(a) Ensure security of tenure, by adopting anti-eviction laws and improving the regulatory framework concerning expropriation;

(b) Conduct decentralized mapping of various users' land rights and strengthen customary systems of tenure;

(c) Adopt tenancy laws to protect tenants from eviction and from excessive levels of rent;

(d) Respect the rights of special groups, such as indigenous peoples, fisherfolk, herders and pastoralists, for whom the protection of commons is vital;

(e) Prioritize development models that do not lead to evictions, disruptive shifts in land rights and increased land concentration, and ensure that all land investment projects are consistent with relevant obligations under international human rights law (A/HRC/13/33/Add.2);

(f) Refrain from criminalizing the non-violent occupation of land by movements of landless people;

(g) Implement redistributive land reform where a high degree of land ownership concentration is combined with a significant level of rural poverty attributable to landlessness or to the cultivation of excessively small plots of land by smallholders, and supporting beneficiaries of land redistribution to ensure that they can make a productive use of their land; and

(h) Regulate land markets to prevent the impacts of speculation on land concentration and distress sales by indebted farmers.

\section{Seeds}

Guaranteeing food security in the future requires that we support crop genetic diversity, including agrobiodiversity (A/64/170). This is particularly important for small-scale farmers in developing countries, who still overwhelmingly rely on seeds which they save from their own crops and which they donate, exchange or sell. In order to ensure that the 
development of the intellectual property rights regime and the implementation of seed policies at the national level are compatible with the right to food, States should:

(a) Make swift progress towards the implementation of farmers' rights, as defined in article 9 of the International Treaty on Plant Genetic Resources for Food and Agriculture;

(b) Not allow patents on plants and establish research exemptions in legislation protecting plant breeders' rights;

(c) Ensure that their seed regulations (seed certification schemes) do not lead to an exclusion of farmers' varieties; and

(d) Support and scale up local seed exchange systems such as community seed banks and seed fairs, and community registers of peasant varieties.

Donors and international institutions should assist States in implementing the above recommendations, and, in particular:

(a) Support efforts by developing countries to establish a sui generis regime for the protection of intellectual property rights which suits their development needs and is based on human rights;

(b) Fund breeding projects on a large diversity of crops, including orphan crops, as well as on varieties for complex agroenvironments such as dry regions, and encourage participatory plant breeding;

(c) Channel an adequate proportion of funds towards research programmes and projects that aim at improving the whole agricultural system and not only the plant (agroforestry, better soil management techniques, composting, water management, good agronomic practices).

\section{Fisheries}

It is urgent that States move towards sustainable resource use while ensuring that the rights and livelihoods of small-scale fishers and coastal communities are respected and that the food security of all groups depending on fish is improved (A/67/268). To reach this objective, States should:

(a) Respect the existing rights of artisanal and small-scale fishing communities;

(b) Refrain from taking measures, including large-scale development projects, that may adversely affect the livelihoods of inland and marine small scale fishers, their territories or access rights, unless their free, prior and informed consent is obtained;

(c) Strengthen access to fishery resources and improve the incomes of smallscale fishing communities by regulating the industrial fishing sector to protect the access rights of traditional fishing communities.

(d) Protect labour rights in the fishing industry;

(e) When engaging in fishing access agreements, agree to introduce provisions concerning conditions of work in the fishing industry and support efforts of coastal States to regulate the fishing practices of industrial vessels operating in exclusive economic zones.

(f) Implement their commitments under the Plan of Implementation of the World Summit on Sustainable Development, including to reduce their fishing capacity and to create marine protected areas;

(g) Implement the Agreement on Port State Measures to Prevent, Deter and Eliminate Illegal, Unreported and Unregulated Fishing; and 
(h) Reduce the proportion of fish used for fishmeal purposes.

\section{B. Supporting local food systems}

\section{Reinvestment in agriculture}

Reinvestment in agriculture and rural development should effectively contribute to the realization of the right to food $(\mathrm{A} / \mathrm{HRC} / 12 / 31)$. In order to achieve this important goal, the international community should:

(a) Channel adequate support to sustainable farming approaches that benefit the most vulnerable groups and that are resilient to climate change;

(b) Prioritize the provision of public goods, such as storage facilities, extension services, means of communications, access to credit and insurance, and agricultural research;

(c) In countries facing important levels of rural poverty and in the absence of employment opportunities in other sectors, establish and promote farming systems that are sufficiently labour-intensive to contribute to employment creation (A/HRC/13/33/Add.2); and

(d) Ensure that investment agreements contribute to reinforcing local livelihood options and to environmentally sustainable modes of agricultural production.

\section{Agroecology}

Moving towards sustainable modes of agricultural production is vital for future food security and an essential component of the right to food. Agroecology has enormous potential in that regard (A/HRC/13/33/Add.2). States should support the adoption of agroecological practices by:

(a) Building on the complementary strengths of seeds-and-breeds and agroecological methods, allocating resources to both, and exploring the synergies, such as linking fertilizer subsidies directly to agroecological investments on the farm ("subsidy to sustainability");

(b) Supporting decentralized participatory research and the dissemination of knowledge by relying on existing farmers' organisations and networks.

(c) Increase the budget for agroecological research at the field level, farm and community levels, and national and sub-national levels; and

(d) Assess projects on the basis of a comprehensive set of performance criteria (impacts on incomes, resource efficiency, impacts on hunger and malnutrition, empowerment of beneficiaries, etc.) in addition to classical agronomical measures.

\section{Support small-holder farmers}

The realization of the right to food for all will require proactively engaging in public policies aimed at expanding the choices of smallholders to sell their products at a decent price (A/HRC/13/33). To achieve this, States should:

(a) Strengthen local and national markets and support continued diversification of channels of trading and distribution;

(b) Support the establishment of farmers' cooperatives and other producer organizations (A/66/262); 
(c) Establish or defend flexible and efficient producer marketing boards under government authority but with the strong participation of producers in their governance;

(d) Encourage preferential sourcing from small-scale farmers through fiscal incentives or by making access to public procurement schemes conditional on the bidders' compliance with certain sourcing requirements.

\section{Contract farming}

To ensure that contract farming and other business models support the right to food (A/66/262), Governments should ensure that regulatory oversight keeps pace with the level of the expansion and the complexity of business models. In particular, States should:

(a) Regulate key clauses of contracts, including those concerning price fixing, quality grading and the conditions under which inputs are provided, and the reservation of a portion of land for the production of food crops for self-consumption;

(b) Monitor labour conditions in contract farming;

(c) Link their support for contract farming to compliance with environmental conditions, such as reduced use of chemical fertilizers or the planting of trees, or to the adoption of a business plan that provides for a gradual shift to more sustainable types of farming; and

(d) Set up forums in which the fairness of food chains could be discussed among producers, processors, retailers and consumers to ensure that farmers are paid fair prices for the food they produce.

\section{Agricultural workers}

To guarantee that those working on farms can be guaranteed a living wage, adequate health and safe conditions of employment (A/HRC/13/33), States should:

(a) Improve the protection of agricultural workers by ratifying all ILO conventions relevant for the agrifood sector and ensuring that their legislation sets a minimum wage corresponding at least to a "living wage"; and

(b) Monitor compliance with labour legislation by devoting appropriate resources for an effective functioning of labour inspectorates in agriculture, and taking the requisite measures to reduce to the fullest extent possible the number of workers outside the formal economy to ensure that agricultural workers are progressively protected by the same social security schemes applicable to other industries.

\section{Deploying national strategies}

\section{National strategies}

States should build national strategies for the realization of the right to adequate food, which should include mapping of the food-insecure, adoption of relevant legislation and policies with a right-to-food framework, establishment of mechanisms to ensure accountability, and the establishment of mechanisms and processes which ensure real participation of rights-holders, particularly the most vulnerable, in designing and monitoring such legislation and policies (A/68/268). For national strategies to be effective, they should be:

(a) Grounded in law, through the adoption of right to food/food and nutrition security framework laws and ideally through the inclusion of the right to food in national constititions; 
(b) Multisectoral and inclusive, ensuring the coordination amongst Government ministries and institutions and allowing for meaningful participation of civil society in their formulation and monitoring;

(c) Adequately funded.

(d) Monitored also by national courts and national human rights institutions as well as through social audits and community-based monitoring at the local level.

\section{Human Rights Impact Assessments}

To ensure consistency between domestic policies aimed at the full realization of the right to food and external policies in the areas of trade, investment, development and humanitarian aid, States should establish mechanisms that ensure that the right to food is fully taken into account in those policies. The Special Rapporteur has presented Guiding Principles on Human Rights Impact Assessments, based on a range of consultations with governmental and non-governmental actors, which provide guidance as to how to conduct such assessments, both ex-ante and ex-post (A/HRC/19/59/Add.5).

\section{Women's rights}

In order to strengthen the protection of the right to food of women $(\mathrm{A} / \mathrm{HRC} / 22 / 50)$, States should:

(a) Remove all discriminatory provisions in the law, combat discrimination that has its source in social and cultural norms, and use temporary special measures to accelerate the achievement of gender equality;

(b) Recognize the need to accommodate the specific time and mobility constraints on women as a result of the existing gender roles, while at the same time redistributing the gender roles by a transformative approach to employment and social protection;

(c) Mainstream a concern for gender in all laws, policies and programs, where appropriate, by developing incentives that reward public administrations which make progress in setting and reaching targets in this regard;

(d) Adopt multisector and multi-year strategies that move towards full equality for women, under the supervision of an independent body to monitor progress, relying on gender-disaggregated data in all areas relating to the achievement of food security.

\section{Social protection}

The provision of social protection can substantially contribute to the realization of the right to food (A/68/268, A/HRC/12/31). States should:

(a) Guarantee the right to social security to all, without discrimination, through the establishment of standing social protection schemes;

(b) Ensure that, when targeted schemes are adopted, they are based on criteria that are fair, effective and transparent;

(c) Define benefits under national social protection systems as legal entitlements, so that individual beneficiaries are informed about their rights under social programs and have access to effective and independent grievance redressal mechanisms;

(d) Ensure that the design of social protection schemes is effectively transformative of existing gender roles (A/HRC/22/50); and 
(e) Put in place a global reinsurance mechanism, creating an incentive for countries to set up robust social protection programmes for the benefit of their populations.

\section{Nutrition}

To reshape food systems for the promotion of sustainable diets and effectively combat the different faces of malnutrition (A/HRC/19/59), States should:

(a) Adopt statutory regulation on the marketing of food products, as the most effective way to reduce marketing of foods high in saturated fats, trans-fatty acids, sodium and sugar (HFSS foods) to children, and restrict marketing of these foods to other groups; (b) Impose taxes on soft drinks (sodas), and on HFSS foods, in order to subsidize access to fruits and vegetables and educational campaigns on healthy diets;

(c) Adopt a plan for the complete replacement of trans-fatty acids with polyunsaturated fats;

(d) Review the existing systems of agricultural subsidies, in order to take into account the public health impacts of current allocations, and use public procurement schemes for school-feeding programmes and for other public institutions to support the provision of locally sourced, nutritious foods; and

(e) Transpose into domestic legislation the International Code of Marketing of Breast-milk Substitutes and the WHO recommendations on the marketing of breast-milk substitutes and of foods and non-alcoholic beverages to children, and ensure their effective enforcement.

The private sector should:

(a) Comply fully with the International Code of Marketing of Breast-milk Substitutes, and comply with the WHO recommendations on the marketing of foods and non-alcoholic beverages to children, even where local enforcement is weak or non-existent;

(b) Abstain from imposing nutrition-based interventions where local ecosystems and resources are able to support sustainable diets, and systematically ensure that such interventions prioritize local solutions;

(c) Shift away from the supply of HFSS foods and towards healthier foods and phase out the use of trans-fatty acids in food processing.

\section{Shaping an enabling international environment}

\section{Food price volatility}

The international community should find ways to better manage the risks associated with international trade and ensure that least-developed and net food-importing developing countries are better protected from the volatility of international market prices. To combat volatility on international markets $(\mathrm{A} / \mathrm{HRC} / 12 / 3)$, the international community should:

(a) Encourage the establishment of food reserves at the local, national or regional levels;

(b) Improve the management of grain stocks at the global level, including improved information about and coordination of global grain stocks to limit the attractiveness of speculation;

(c) Establish an emergency reserve that would allow the World Food Programme to meet humanitarian needs; 
(d) Explore ways to combat unhealthy speculation on the futures markets of agricultural commodities through commodity index funds.

\section{A new framework for trade and investment in agriculture}

The realization of the right to food requires designing trade rules that support the transition toward more sustainable agricultural practices. The multilateral trade regime as well as regional and bilateral trade agreements must allow countries to develop and implement ambitious food security policies including public food reserves, temporary import restrictions, active marketing boards, and safety net insurance schemes, in support of the progressive realization of the right to food (A/HRC/10/5/Add.2). In this regard, States should:

(a) Limit excessive reliance on international trade and build capacity to produce the food needed to meet consumption needs, with an emphasis on small-scale farmers;

(b) Maintain the necessary flexibilities and instruments, such as supply management schemes, to insulate domestic markets from the volatility of prices on international markets; and

(c) Encourage national parliaments to hold regular hearings about the positions adopted by the government in trade negotiations, and ensure that their undertakings under the WTO framework are fully compatible with the right to food;

(d) Fully implement the Marrakesh Ministerial Decision on Measures concerning the possible negative effects of the reform programme on least developed and net foodimporting developing countries (NFIDCs) and, in order for it to be fully effective, ensure that it include a mechanism to systematically monitor the impact of the Agreement on Agriculture reform process on NFIDCs.

\section{Regulating agribusiness}

States should take steps towards the establishment of a multilateral framework regulating the activities of commodity buyers, processors, and retailers in the global food supply chain, including the setting of standards by these actors and their buying policies (A/HRC/13/33). In particular, States should use competition law in order to combat excessive concentration in the agribusiness sector. This requires having in place competition regimes sensitive to excessive buyer power in the agrifood sector, and devising competition authorities with mechanisms that allow for affected suppliers to bring complaints without fear of reprisal by dominant buyers.

Private actors of the agribusiness sector should refrain from practices that constitute an undue exercise of buyer power, as identified by the States in which they operate, and should:

(a) Seek to conclude international framework agreements with global unions;

(b) Consider unilateral undertakings to monitor compliance with ILO standards in the supply chain, while supporting their suppliers in achieving compliance;

(c) Engage in chain-wide learning to assure that participation in the chain is profitable for all involved, including small-scale producers;

(d) Involve smallholders in the elaboration of and compliance with food safety, labour or environmental standards; and

(e) Promote fair trade through increased shelf space and information campaigns. 


\section{Agrofuels}

The international community should reach a consensus on agrofuels, based not only on the need to avoid the negative impact of the development of agrofuels on the international price of staple food commodities, but also on the need to ensure that the production of agrofuels respects the full range of human rights and does not result in distorted development in producer countries. Public incentives for the production of crop-based biofuels must be reduced and eventually removed, while only those advanced biofuels that do not compete with food production for land or other resources should be incentivised.

\section{Food aid and development cooperation}

International aid remains an important component of the right to food (A/HRC/10/5). Donor States should:

(a) Maintain and increase levels of aid calculated as Official Development Assistance as a percentage of GDP;

(b) Provide food aid on the basis of an objective assessment of the identified needs in developing countries;

(c) Fully respect the principle of ownership in their development cooperation policies by aligning these policies with national strategies for the realization of the right to food;

(d) Promote the right to food as a priority for development cooperation. 